\title{
Issues with Designing Dementia-Friendly Interfaces
}

\author{
Claire Ancient, Alice Good \\ University of Portsmouth, School of Computing, Portsmouth, United Kingdom \\ \{claire.ancient, alice.good\}@port.ac.uk
}

\begin{abstract}
People with dementia are a rapidly growing demographic. In a world which is increasingly dependent on computing, this large group of people is becoming technologically isolated, due to the ill-suited design of interfaces. This paper looks at the possible 'roadblocks' which need to be considered when designing interfaces in order to ensure they are dementia-friendly. By considering the unique needs of a person with dementia, designers can ensure that their software is accessible to this demographic, hence potentially reducing the feelings of technological exclusion.
\end{abstract}

Keywords: Dementia, Interface Design, Accessibility

\section{Introduction}

Dementia is a degenerative brain condition which is not a natural part of the aging process. Generally, the symptoms of dementia include memory loss, communication problems and mood changes. However, each person will experience the condition differently depending on the type of dementia and their individual circumstances [1].

In the next 8 years, the number of people with dementia in the UK is expected to reach 1 million [2]. In a world were computing is increasingly ubiquitous, it is important that all users are catered for when designing interfaces. Research suggests that elderly people are keen to utilise the latest technology [3, 4] in spite of the fact that their understanding of the products is minimal. When this limited knowledge is combined with inappropriately designed interfaces, it could enhance the person with dementia's feelings of technological isolation. The result being an entire demographic which is being alienated by interface designers, possibly leading to a greater divide between the digital native and digital immigrants [5].

Designing interfaces for people with dementia is difficult. It involves a delicate balance of accessibility features, usability features and elements which are designed to improve the user experience. In addition to this, the people with dementia will not only suffer from condition related decline, but also problems linked to the natural aging process. Despite the rapidly increasing number of computer users with dementia, the W3C WAI currently has no specific guidelines designed to make interfaces dementia-friendly [6]. There are existing guidelines which inform the development of interfaces allowing access to people with age-related decline. However, these do not

adfa, p. 1, 2011.

(C) Springer-Verlag Berlin Heidelberg 2011 
take into account the special needs of a person who is living with a diagnosis of dementia.

The lack of definitive guidelines for designing dementia-friendly interfaces is understandable. As the average age of a group of people rises, the diversity of their individual needs increases [7,8]. This makes designing a "one size fits all" interface challenging.

This paper utilises existing literature, together with observations from a pilot study [9] in order to discuss the possible implications of dementia on the design of interfaces. It considers the three possible areas where dementia will have an impact on the design of interfaces: cognitive impairments, motor impairments and visual impairments. This study is part of a wider research project with the aim to produce applications designed to improve the well-being of people with mental health problems (including dementia). By ensuring the applications are dementia-friendly, the researchers are hoping to maintain the focus on improving well-being, rather than reducing it through inappropriate interface design.

\section{Accessibility Considerations}

When considering accessibility for older people (regardless of a dementia diagnosis), three different areas should to be considered: cognitive impairments, motor impairments and visual impairments. However, during interaction with an interface multiple abilities are brought into play simultaneously [7], with some abilities interacting with each other whilst others compensate for impairments. Therefore, these categories should be considered both in isolation and holistically to obtain a complete overview.

One of the main symptoms of dementia is short term memory loss [1]. Therefore, dementia-friendly interfaces need to account for this diminished ability. Interfaces should minimise the amount of information which the person with dementia is required to remember. The need to remember the relative position within the system could leave the person with dementia feeling disorientated if they fail to recall their location.

Older, inexperienced computer users will often struggle with new jargon [10], this will be accentuated for people with dementia who will sometimes have problems finding the correct word [1]. Ziefle found that when elderly people encounter unfamiliar items in a menu, they would have to learn both the new name together with its relative location [4]. This will be particularly challenging to people with dementia as the capacity to formulate new memories is significantly diminished.

Due to the similarities in symptoms with Parkinson's disease, the consideration of motor impairments is particularly important for people who have been diagnosed with Lewy body dementia [11]. This can accentuate the slower movements experienced during older age. It is essential to consider the increased response time of people with dementia (especially Lewy body dementia), when an interface expects a response within a specific length of time - such as 'time-outs' when completing an online form.

Often, older people struggle with complex movements, particularly if they are novel movements [7]. During a pilot study by Ancient et al. [9] it was observed that 
an older person struggled with the "pinch-zoom" functionality of touch screen computing. Consideration of this is especially important for people who have dementia as some complex movements may always be novel to them regardless of the number of times they have been demonstrated. In addition, people with reduced motor skills often struggle to cope with manoeuvring scroll bars resulting in large jumps of the screen position, leading to disorientation $[4,7]$.

Hawthorn [7] discusses the limited typing ability of elderly people as an interface "barrier". During the pilot study, one participant commented on his struggle to type, suggesting that younger people are used to typing on smart devices, whereas his generation was not and as such found difficulty typing quickly.

As people grow older, their eyesight declines. There are significant declines in visual acuity (especially within a dimly lit environment), an increased sensitivity to glare, a reduction in the field of view, a decline in the ability to rapidly adjust to changing light and a decline in sensitivity to colours [7, 12]. In the case of people with dementia, the occipital lobe (which manages the visual information which is conveyed by the eyes) may become damaged. This leads to increased problems with perception as colour, shape and movement are processed by this part of the brain [13].

With regards to text size, it is generally agreed that the larger the font, the easier it is for elderly people to see [10]. However, care should be taken that the font is not increased to the point where scrollable windows are required to compensate for the bigger space needed to contain the text.

It is important to ensure that the readability is improved for all elderly users, with suggestions of reducing the density of the text [4]. However, there is increased significance to people with dementia as damage to the occipital lobe could cause difficulties in identifying objects and text [13]. By improving the readability, the brain will be provided with as much information as possible to produce a more accurate image.

\begin{tabular}{|c|c|c|}
\hline Category & $\begin{array}{c}\text { Considerations for Elderly } \\
\text { People } \\
\end{array}$ & $\begin{array}{c}\text { Additional Considerations for } \\
\text { People with Dementia }\end{array}$ \\
\hline \multirow{2}{*}{$\begin{array}{c}\text { Cognitive } \\
\text { Impairments }\end{array}$} & & $\begin{array}{l}\text { - Short term memory loss }[1] \text { : } \\
\text { - Reduced ability to remem- } \\
\text { ber items } \\
\text { - Disorientation when trying } \\
\text { to recall relative location in } \\
\text { the system }\end{array}$ \\
\hline & $\begin{array}{l}\text { - Sometimes struggle to remem- } \\
\text { ber terminology [10] - often } \\
\text { resulting in the need to re- } \\
\text { member both the name and lo- } \\
\text { cation in the menu [4] }\end{array}$ & $\begin{array}{l}\text { - Often struggle to find the cor- } \\
\text { rect word, enhancing the diffi- } \\
\text { culty with terminology [1]. } \\
\text { - Reduced capacity to formulate } \\
\text { new memories - difficult to } \\
\text { learn both new word and menu } \\
\text { location. }\end{array}$ \\
\hline $\begin{array}{c}\text { Motor } \\
\text { Impairments }\end{array}$ & - Movements are slower & $\begin{array}{l}\text { - Slower movements can be } \\
\text { accentuated by symptoms of } \\
\text { dementia with Lewy bodies }\end{array}$ \\
\hline
\end{tabular}




\begin{tabular}{|c|c|c|}
\hline & & $\begin{array}{l}\text { (which are similar to Parkin- } \\
\text { son's disease) [11] }\end{array}$ \\
\hline & $\begin{array}{l}\text { - Elderly people struggle with } \\
\text { complex movements - particu- } \\
\text { larly if they are novel [7]. }\end{array}$ & $\begin{array}{l}\text { - May not be able to learn new } \\
\text { complex motor skills. }\end{array}$ \\
\hline & $\begin{array}{l}\text { - Find manipulating scroll-bars } \\
\text { challenging, leading to disori- } \\
\text { entation }[4,7]\end{array}$ & \\
\hline & $\begin{array}{l}\text { - Reduced ability for typing [7]. } \\
\text { - Comments made during a pilot } \\
\text { study [9] suggest typing on a } \\
\text { tablet or smartphone is not } \\
\text { natural for older people. }\end{array}$ & \\
\hline & $\begin{array}{l}\text { - As people age, their eyesight } \\
\text { ability declines }[7,12]\end{array}$ & $\begin{array}{l}\text { - Damage to occipital lobe can } \\
\text { cause problems with percep- } \\
\text { tion due to problems with in- } \\
\text { terpretation in the brain [13] }\end{array}$ \\
\hline $\begin{array}{c}\text { Visual } \\
\text { Impairments }\end{array}$ & $\begin{array}{l}\text { - Larger text is easier to read for } \\
\text { older people [10] } \\
\text { - Should avoid text becoming } \\
\text { too big, so there is no re- } \\
\text { quirement for scrolling } \\
\text { windows }\end{array}$ & \\
\hline & & $\begin{array}{l}\text { - Maximise readability in order } \\
\text { to provide the occipital lobe } \\
\text { with enough information to } \\
\text { provide an accurate reading } \\
\text { [13] }\end{array}$ \\
\hline
\end{tabular}

Table 1. Summary of Key Design Considerations

\section{Conclusion}

Given the range of requirements for this user group, designing dementia-friendly interfaces will not be easy. However, with the number of people with dementia increasing, it will become a necessity of the interface design process, if we are to strive towards inclusiveness. By accounting for the additional needs of this important demographic, interface designers may be able to reduce feelings of technological isolation and improve interaction with modern technologies, by enabling a positive user experience.

The aim of future research will be to devise a set of guidelines to aid interface designers with the development of dementia-friendly interfaces. The diverse nature of 
dementia symptoms together with the increased variability of individual needs as people get older certainly make this a difficult challenge.

Research has shown that older people are not averse to adopting new technologies $[3,4]$, if designers can ensure that their interfaces are accessible to people with dementia, a new realm of possible treatments aimed at mitigating the symptoms could be developed.

\section{References}

1. Alzheimer's Society, What is Dementia? http://www.alzheimers.org.uk/site/scripts/documents_info.php?documentID=106.

2. Alzheimer's Society, Demography, http://www.alzheimers.org.uk/site/scripts/documents_info.php?documentID=412.

3. Chou, J., Hsiao, S.: A Usability Study on Human-Computer Interface for Middle-aged Learners. Computers in Human Behavior, 23, 2040-2063 (2007).

4. Ziefle, M.: Information Presentation in Small Screen Devices: The Trade-Off between Visual Density and Menu Foresight. Applied Ergonomics, 41, 719-730 (2010)

5. Holsapple, C., Pakath, R., Sasidharan, S.: A Website Interface Design Framework for the Cognitively Impaired: A Study In The Context Of Alzheimer's Disease. Journal of Electronic Commerce Research, 6, 291-303 (2005).

6. Web Accessibility Initiative, Web Content Accessibility Guidelines. http://www.w3.org/WAI/intro/wcag.php

7. Hawthorn, D.: Possible Implications of Aging for Interface Designers. Interacting with Computers, 12, 507-528 (2000)

8. Gregor, P., Newell, A. F., Zajicek, M.: Designing for Dynamic Diversity - Interfaces for Older People/ In: Proceedings of the Fifth International ACM Conference on Assistive Technologies, pp 151-156. ACM Press, New York (2002)

9. Ancient, Claire, Good, Alice, Wilson, Clare, and Fitch, Tineke (2013) Can Ubiquitous Devices Utilising Reminiscence Therapy be Used to Promote Well-being in Dementia Patients? An Exploratory Study. In Ambient Assisted Living, part of HCI International 2013, 21st - 25th July 2013, Las Vegas.

10. Dickinson, A., Newell, A. F., Smith, M. J., Hill, R. L.: Introducing to the over-60s: Developing an Email System for Older Novice Computer Users. Interacting with Computers, 17, 621-642 (2005)

11. Alzheimer's Society, What is Dementia with Lewy Bodies? http://alzheimers.org.uk/site/scripts/documents_info.php?documentID=113

12. Lorenz, A., Oppermann, R.: Mobile Health Monitoring for the Elderly: Designing for Diversity. Pervasive and Mobile Computing, 5, 478-495 (2009)

13. Alzheimer's Society, The Brain and Behaviour. http://alzheimers.org.uk/site/scripts/documents_info.php?documentID=114 